\title{
Systematic Review of Pain in Clinical Practice Guidelines for Management of COPD: A Case for Including Chronic Pain?
}

\author{
Hayley Lewthwaite ${ }^{1, * \mathbb{C}}$, Georgia Williams ${ }^{1}$, Katherine L. Baldock ${ }^{2}$ (D) and Marie T. Williams ${ }^{1}$ (D) \\ 1 Alliance for Research in Exercise, Nutrition and Activity, School of Health Sciences, Division of Health \\ Sciences, University of South Australia, Adelaide 5001, Australia; Georgia.Williams2@sa.gov.au (G.W.); \\ Marie.Williams@unisa.edu.au (M.T.W.) \\ 2 Australian Centre for Precision Health, School of Health Sciences, Division of Health Sciences, University of \\ South Australia, Adelaide 5001, Australia; Katherine.Baldock@unisa.edu.au \\ * Correspondence: Hayley.Lewthwaite@mymail.unisa.edu.au; Tel.: +61-1(514)-398-4184
}

Received: 17 December 2018; Accepted: 19 January 2019; Published: 22 January 2019

\begin{abstract}
Chronic pain is highly prevalent and more common in people with chronic obstructive pulmonary disease (COPD) than people of similar age/sex in the general population. This systematic review aimed to describe how frequently and in which contexts pain is considered in the clinical practice guidelines (CPGs) for the broad management of COPD. Databases (Medline, Scopus, CiNAHL, EMbase, and clinical guideline) and websites were searched to identify current versions of COPD CPGs published in any language since 2006. Data on the frequency, context, and specific recommendations or strategies for the assessment or management of pain were extracted, collated, and reported descriptively. Of the 41 CPGs (English $n=20)$ reviewed, $16(39 \%)$ did not mention pain. Within the remaining $25 \mathrm{CPGs}$, pain was mentioned 67 times (ranging from 1 to 10 mentions in a single CPG). The most frequent contexts for mentioning pain were as a potential side effect of specific pharmacotherapies (22 mentions in 13 CPGs), as part of differential diagnosis (14 mentions in 10 CPGs), and end of life or palliative care management (7 mentions in 6 CPGs). In people with COPD, chronic pain is common; adversely impacts quality of life, mood, breathlessness, and participation in activities of daily living; and warrants consideration within CPGs for COPD.
\end{abstract}

Keywords: chronic obstructive pulmonary disease; pain; chronic pain; symptom palliation; clinical guideline

\section{Introduction}

In people with chronic obstructive pulmonary disease (COPD), persistent pain is a common clinical issue adversely impacting daily function, symptom burden, and quality of life [1-3]. To date, there are at least 34 studies [1,4-36] and two systematic reviews [2,3] available that report direct estimates of pain prevalence in people with COPD (Figure 1). Prevalence rates for pain vary markedly and range between 21 to $82 \%$ (Figure 1) with a mean pooled estimate of $66 \%$ (95\% Confidence Interval (CI) 44-85\%) [2]. These estimates are likely influenced by the clinical context of the sample (e.g., stable, acutely unwell, or end of life), sampling source (e.g., outpatients, pulmonary rehabilitation, and population), assessment instrument, and focal period (e.g., past week, month, and year). Excluding studies where the prevalence is likely to reflect acute pain associated with hospital presentation or end of life care, the majority of studies reflect persistent or chronic pain reported by people participating in pulmonary rehabilitation, attending routine outpatient appointments, or of the broader community. Compared to the general community, large population-based studies report higher rates of persistent pain in people with COPD for (1) "usual" chronic non-cancer pain ( $34.9 \%$ COPD versus $14 \%$ control; 
odds ratio (OR) 1.56, 95\%CI 1.40-1.74) [29]; (2) chronic low back pain over 12 months (44.8\% COPD versus $28.4 \%$ control; OR $1.38,95 \%$ CI $1.16-1.64$ ) [33]; (3) chronic neck pain over 12 months (40.5\% COPD versus $26.1 \%$ control; OR 1.21, 95\%CI 1.02-1.45) [33]; and (4) chronic pain lasting longer than six months (51.8\% COPD versus $25.9 \%$ control; OR 1.56, 95\%CI 1.30-1.92) [34]. People with COPD who have persistent pain have been reported to have significantly higher pain medication use over a 12 month period and higher usage of pain-related services [37].

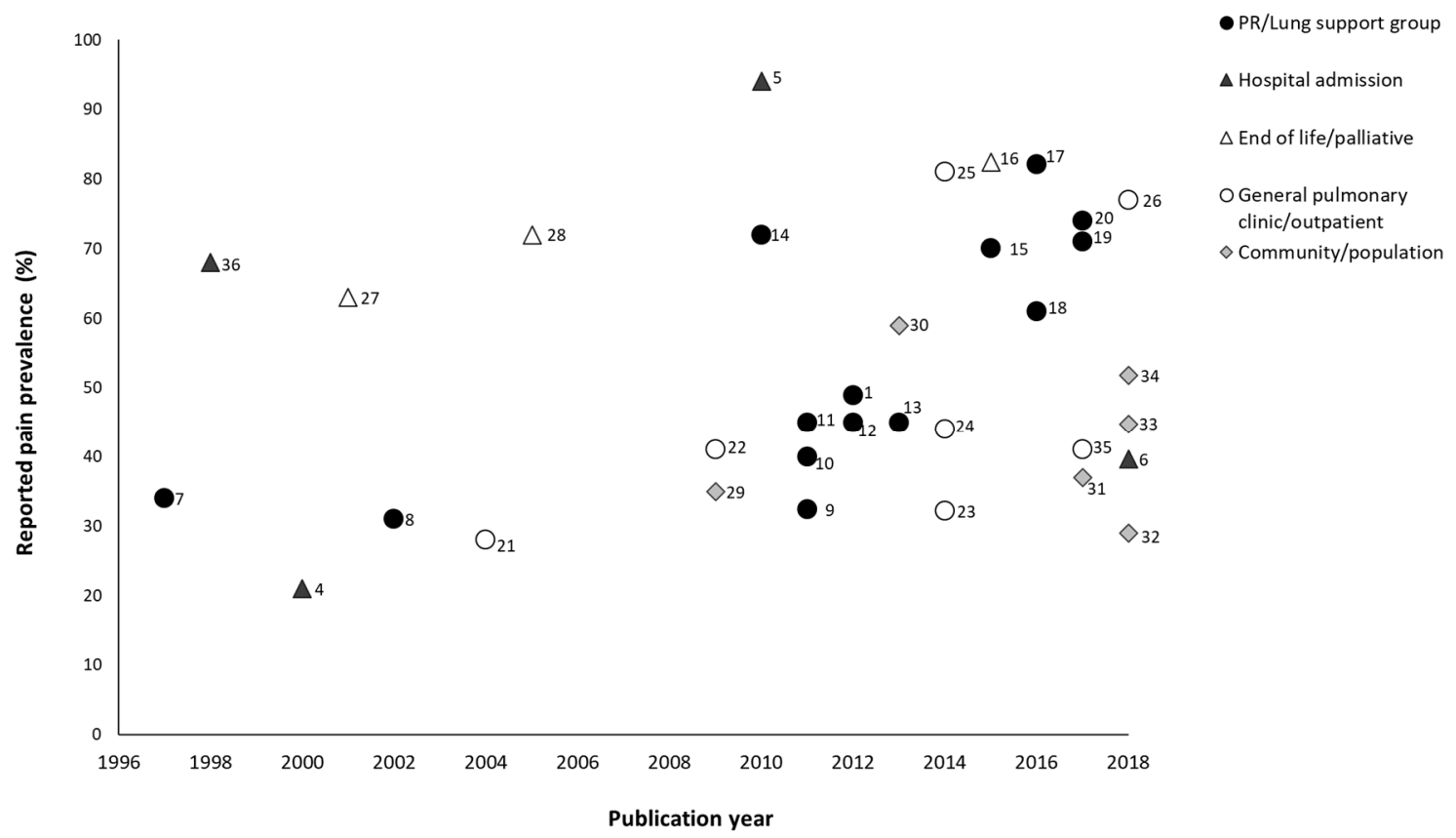

Figure 1. Pain prevalence reported within studies by the clinical population. PR, pulmonary rehabilitation.

The aetiology underpinning persistent pain in people with COPD is complex and underexplored. Systemic inflammatory processes inherent in COPD are likely to provide the foundation for pain susceptibility $[1,3,38]$. Previous authors have proposed a range of potential mechanisms that may cause, contribute to, or maintain persistent pain in people with COPD, including altered respiratory and musculoskeletal mechanics [38], postural deviations, osteoporosis, compression fractures [39], vertebral deformation, costovertebral arthropathy, [32], central sensitisation [1,38], side effects of prolonged steroid use [38], the presence of comorbid conditions including anxiety and depression [34], and personal habitus (sex and socioeconomic factors) [33]. For people with COPD attending pulmonary rehabilitation programs, musculoskeletal conditions (e.g., arthritis, back problems, and muscle cramps) have been proposed as the commonest cause of persistent pain, with low back, trunk and neck, and lower extremities described as the most common locations $[1,11,32,33,40]$.

Roberts et al. (2013) noted limited discussion concerning pain in the international clinical practice guidelines (CPGs) for the management of COPD [30]. Given the increasing attention over the past decade concerning the prevalence and clinical implications of persistent pain in people with COPD, we were interested to know, in national and international CPGs for the broad management of COPD, (1) how often and in which contexts pain is mentioned and (2) whether recommendations and strategies are provided around the assessment or management of pain.

\section{Materials and Methods}

The review protocol was developed using the preferred reporting items for systematic reviews and meta-analyses (PRISMA-P) guidelines [41] and was registered with the International Prospective Register of Systematic Reviews (PROSPERO CRD42016044103). 


\subsection{Eligibility}

Clinical practice guidelines (CPGs) were eligible for inclusion within this review if they were (1) the most recent version for the broad management of COPD and (2) published by an authoritative medical, scientific, or government body. There were no limitations set for the language of publication. Guidelines that were focused on specific aspects of disease management such as acute COPD exacerbations, pulmonary rehabilitation, or domiciliary oxygen were excluded. The original review was undertaken during 2017 with the initial search strategy limited to publicly available CPGs published in the previous decade (January 2006 to December 2016). In late 2018, an additional search was undertaken to identify any new CPGs or updated versions of the CPGs included in the original review.

\subsection{Information Sources and Search Strategy}

The search strategy was based on a previous systematic review of COPD CPGs [42]. For the current review, the strategy was reviewed, updated, and run by a single member of the research team (G.W.). The search strategy for OVID Medline is provided in Table S1 of the Supplementary Materials. Four electronic databases (Ovid Medline, EMbase, CiNAHL, and Scopus) were searched using search terms for the population of interest (COPD, pulmonary emphysema, or pulmonary disease chronic obstructive) and publication type (guideline, consensus, position statement, guidance, or standard). The reference lists of systematic reviews identified by the electronic database search were hand searched for eligible CPGs. Seven publicly available CPG databases were also searched (The National Institute for Health and Care Excellence, Clinical Practice Guidelines Portal, National Guideline Clearing House, Guidelines International Network, Scottish Intercollegiate Guidelines Network, Canadian Medical Association Infobase: Clinical Practice Guidelines, and the International Primary Care Respiratory Group).

\subsection{Document Selection}

A single reviewer (G.W.) screened the English titles of references retained from the searches to determine preliminary eligibility and to remove duplicates. Two independent reviewers (G.W. and H.L.) assessed the remaining abstracts for eligibility, and subsequently, for references retained (i.e., eligible for inclusion or could not be confidently excluded), accessed and reviewed full-text versions of the CPGs. Discrepancies were resolved by discussion. For references in languages other than English, the full text was obtained and a single reviewer (G.W.) assisted a person fluent in the language to determine eligibility.

\subsection{Data Collection}

A data extraction template was developed a priori for the purpose of this study. The extraction process was pilot tested on three randomly selected CPGs by two independent reviewers (G.W. and H.L.). Following refinement of the template, two independent reviewers (G.W. and H.L.) completed the data extraction for CPGs published in English and met to resolve disagreements. For guidelines published in a language other than English, a translator fluent in the language extracted data with the assistance of a single reviewer (G.W.). Data were extracted for three domains: (1) CPG demographics (title, name of developing body, year, version, country of origin, and language of publication); (2) the frequency of mention and context of the word "pain" (verbatim) in the main body of CPG or supplemental material; and (3) the presence of specific recommendations or strategies for the assessment or management of pain.

\subsection{Data Analysis}

Data extracted regarding guideline demographics and the frequency and context of the mention of "pain" in CPGs were collated and reported descriptively. Where "pain" was mentioned in CPGs, 
the specific contexts were synthesized into common categories, including pain assessment and management. Findings were tabulated for comparison across guidelines.

\section{Results}

The initial electronic database search identified 596 unique references after removal of duplicates with 44 CPGs eligible for inclusion (Figure 2). Despite meeting eligibility criteria, two CPGs were unable to be accessed due to geographic restrictions for purchase outside the United States and Japan $[43,44]$ and a single CPG was unable to be translated from Thai [45]. Therefore, a total of 41 CPGs were included in this review, 20 published in English and 21 in a language other than English (Figure 2). The complete list of included CPGs is available in Table S2 of Supplementary Materials.

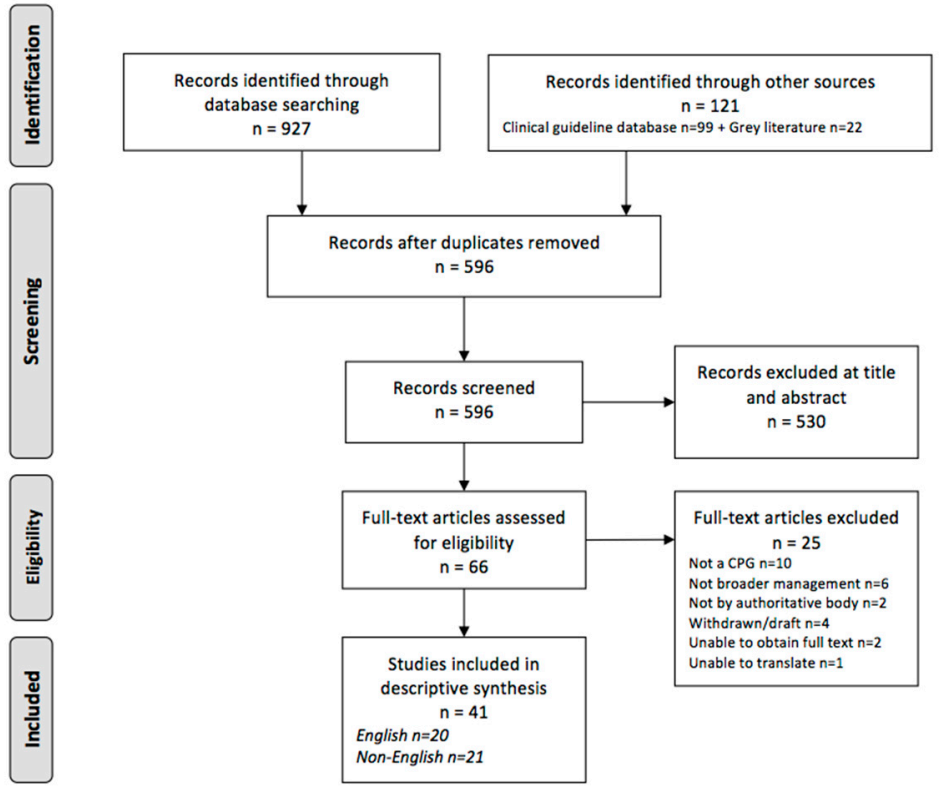

Figure 2. The outcome of the search strategy leading to COPD clinical practice guidelines (CPG) eligible for this review.

\subsection{Frequency and Context of the Mention of "Pain"}

Of the 41 CPGs, 16 CPGs did not mention the term pain (39\%). Of the 25 (61\%) CPGs that mentioned "pain", there were a total of 67 mentions, ranging from one mention in 10 CPGs to 10 mentions in a single guideline [46]. The verbatim mention of "pain" in CPGs is presented in Table S3 of the Supplementary Materials.

Mentions of "pain" in CPGs were most commonly in the context of adverse side effects of pharmacotherapies (22 mentions in 13 (32\%) CPGs): phosphodiesterase-4 inhibitors (mentions were $n=10)$, smoking cessation/nicotine replacement therapies $(n=8)$, methylxanthines $(n=2)$, xanthines $(n=1)$, or beta 2 adrenergic receptor agonists $(n=1)$ (Table 1$)$. Other mentions of "pain" were in the context of recommendations for pain assessment (18 mentions in $10(24 \%)$ CPGs) or management (13 mentions in $11(27 \%)$ CPGs) or of indications / contraindications for respiratory function assessments (8 mentions in $5(12 \%)$ CPGs) or were listed as a symptom of COPD (4 mentions in $4(10 \%)$ CPGs) or as a complication (bullae and fractures) of COPD (2 mentions in 2 (5\%) CPGs).

Four guidelines specifically made reference to the commonality or prevalence of pain. The Finnish guideline reported pain is a common symptom of advanced COPD in 30 to $70 \%$ of patients [47]. The German CPG reported pain, dyspnoea, and fatigue to be the most common symptoms in patients in the year before death [48]. The Norway CPG stated that pain is a distressing symptom in advanced COPD [49]. The Dutch CPG reported people with COPD believe they will experience less pain than people with other chronic conditions [46]. 


\subsection{Recommendations and Strategies Provided Around Pain Assessment}

Ten (24\%) CPGs provided recommendations around the assessment of pain (Table 1). Strategies recommended within CPGs for pain assessment were (1) physician to assess pain as part of a differential diagnosis, specific to the assessment of chest pain (mentions were $n=12$ in 9 CPGs) or generalised pain as a symptom of anxiety disorder $(n=1)$; (2) physician to assess for thoracic pain as part of screening for pulmonary rehabilitation $(n=1)$; (3) self-report questionnaires for problematic sputum causing painful cough $(n=1) ;(4)$ the Borg rating scale as a tool to assess pain in a non-specific context $(n=1)$; and (5) cardiopulmonary exercise tests to differentiate the cause of exercise limitations $(n=1)$.

\subsection{Recommendations and Strategies Provided Around Pain Management}

Eleven (27\%) CPGs provided recommendations around pain management (Table 1). Strategies recommended within CPGs for pain management were (1) palliative care (mentions were $n=5$ in 5 CPGs), (2) pharmacotherapies: opioids for palliative care ( $n=2$ in 2 CPGs) or epidural analgesics for postoperative care $(n=1),(3)$ surgery $(n=1),(4)$ patient education for preoperative care $(n=1)$, (5) positive expiratory pressure (PEP) therapy as a strategy to increase ventilation for people with pain $(n=1)$, or $(6)$ non-specific reference in the general management of COPD $(n=1)$ or around opioid dosage $(n=1)$.

\subsection{CPGs' Updated or New Since 2017-Has Anything Changed with Respect to Pain?}

Nine CPGs (22\%) included in the original sampling frame (2006-2016) have been updated (Table S2, Supplementary Materials) [50-58], and one new CPG was identified [59]. Within updated or newly identified CPGs, there were nine mentions of "pain". In line with the original review, "pain" was most commonly mentioned in the context of adverse side effects of pharmacotherapies (mentions, $n=7$ ): phosphodiesterase-4 inhibitors $(n=4)$, nicotine replacement therapies $(n=2)$, or methylxanthines $(n=1)$. A single CPG mentioned pain in the context of assessment (physicians to assess chest pain as part of a differential diagnosis) [51], and one guideline mentioned pain associated with various organs as a common symptom in the year before death [52]. 
Table 1. Mentions of "pain" in specific contexts within the clinical practice guidelines for the management of COPD.

\begin{tabular}{|c|c|c|c|c|c|c|c|c|c|c|c|c|c|c|}
\hline \multirow[b]{2}{*}{ Guideline } & \multirow[b]{2}{*}{ Mentions $n=$} & & \multirow{2}{*}{ Symptom } & \multicolumn{3}{|c|}{ Assessment } & \multicolumn{6}{|c|}{ Management } & \multirow{2}{*}{ Drug Effect } & \multirow{2}{*}{ Lung Functior } \\
\hline & & & & Physician DxDx & Question/Scale & CPET & Palliative Care & Pharma & Surgery & Education & PEP & NS & & \\
\hline $\begin{array}{l}\text { Mentions in context }(n=) \\
\text { GOLD: International [60] }\end{array}$ & 1 & & $6(U D+1)$ & $14(U D+1)$ & 3 & 1 & 5 & 3 & 1 & 1 & 1 & 2 & $22(U D+7)$ & 8 \\
\hline Australia and NZ [51,61] & 4 & & & $1^{\wedge}$ & & & 1 & & & & & & 2 & 1 \\
\hline NHG: Netherlands [62] & 2 & & & 2 & & & & & & & & & & \\
\hline Saudi Arabia [63] & 1 & & & & & & & & & & & & 1 & \\
\hline India [64] & 2 & & 1 & 1 & & & & & & & & & & \\
\hline Italy [65] & 1 & & & & & & 1 & & & & & & & \\
\hline VA/DoD: USA [66] & 3 & & & 1 & & & & & & & & & 2 & \\
\hline Finland [47] & 3 & & 1 & & & & 1 & $\begin{array}{c}1 \\
\text { opioids }\end{array}$ & & & & & & \\
\hline Poland [67] & 2 & & & & & & & & 1 & & & & 1 & \\
\hline HAS: France [68] & 2 & & & & & & 1 & & & & & & 1 & \\
\hline Turkey [69] & 1 & & & & & & & & & & & & 1 & \\
\hline Korea $[54,70]$ & 6 & & & & & & & & & & & & 3 & 3 \\
\hline Spain $[71,72]$ & 1 & & & 1 & & & & & & & & & & \\
\hline Czech Republic [73] & 1 & & & & & & & $\begin{array}{c}1 \\
0 \text { ingids }\end{array}$ & & & & & & \\
\hline China [74] & 3 & & & 1 & & & & & & & & 1 & 1 & \\
\hline Chile [75] & 1 & & & 1 & & & & & & & & & & \\
\hline Ukraine [76] & 2 & & & 2 & & & & & & & & & & \\
\hline Algeria [77] & 1 & & & & & & & & & & & & & 1 \\
\hline Norway [49] & 9 & & 2 & 1 & 2 & 1 & & & & & 1 & 1 & 1 & \\
\hline South Africa [78] & 2 & & & & & & & & & $1^{*}$ & & & & 1 \\
\hline United Kingdom [79] & 5 & & & 2 & & & 1 & & & & & & & 2 \\
\hline CTS: Canada $[80,81]$ & 1 & & & & & & & & & & & & 1 & \\
\hline Germany $[48,52]$ & 2 & 1 & $1^{\wedge}$ & & & & & & & & & & 1 & \\
\hline NVALT: Netherlands [46] & 10 & & 1 & 2 & 1 & & & & & & & & 6 & \\
\hline Malaysia [82] & 1 & & & & & & & $\begin{array}{c}1 \\
A N A I^{*}\end{array}$ & & & & & & \\
\hline UD BC: Canada [55] & 1 & & & & & & & & & & & & $1^{\wedge}$ & \\
\hline New Singapore [59] & 1 & & & & & & & & & & & & $1^{\wedge}$ & \\
\hline
\end{tabular}

* Analgesic epidural specific to pre-/post-surgery; ^ pain mention in update of CPG; CPET, cardiopulmonary exercise testing; DxDx, differential diagnosis; PEP, positive expiratory pressure therapy; Pharma, pharmacological; NS, non-specific; Question, questionnaire; and UD, updated CPG. 


\section{Discussion}

Clinical practice guidelines provide recommendations and strategies for the management of chronic diseases based on the best available evidence or consensus of expert opinion. This systematic review identified 41 national and international CPGs for the management of COPD published between 2006-2016, of which, nine had been further updated by the end of 2018 and one new CPG had been developed. Of the original 41 CPGs, 16 (39\%) did not mention the term "pain". When pain was mentioned (CPGs $n=25,61 \%$; mentions $n=67$ ), this was most frequently in the context of adverse reactions to specific pharmacotherapies (22 mentions in 13 (33\%) CPGs). Few CPGs provided recommendations or strategies around pain assessment (18 mentions in $10(24 \%)$ CPGs) or management (13 mentions in 11 (27\%) CPGs) for people with COPD. When recommendations or strategies were provided, these were generally concerned with a differential diagnosis (10 of 10 CPGs providing pain assessment recommendations) or management in advanced COPD or palliative care (6 of 11 CPGs providing pain management recommendations). There were no additional recommendations or strategies specific to pain assessment or management provided in updated or newly developed CPGs.

\subsection{Given the Reported High Prevalence of Persistent Pain in COPD, Why Do So Few CPGs Address This Symptom Beyond Side Effects of Medication, Differential Diagnosis, or Palliative Management?}

It could be expected that CPGs for the broad management of COPD prioritise assessment and intervention approaches that have been proven to alter the clinical course of the disease (i.e., slowing the lung function rate of decline and preventing exacerbations) or palliating disease-related symptoms [50]. As a sequelae of the underlying pathology in COPD, respiratory signs and symptoms such as chronic progressive breathlessness, cough, and sputum production are common [50]. Consequently, CPGs for COPD may be simply and appropriately reflecting the most prevalent symptoms. For example, while estimates vary, in studies that report the frequency of both chronic breathlessness and pain in people with COPD, breathlessness is more prevalent than pain (1) in clinically stable outpatients with COPD (moderate dyspnoea prevalence $94.3 \%$ versus moderate pain prevalence $32.4 \%$ [9]), (2) in COPD participants of pulmonary rehabilitations programs (dyspnoea prevalence $93 \%$ versus pain prevalence $74 \%$ [20]), and (3) in end of life/palliative care settings ("very much" breathlessness $60 \%$ versus $25 \%$ "very much" pain [36]; breathlessness 90-95\% versus pain 34-77\% [83]).

Alternatively, in an environment of ever-increasing scientific literature, the development and update of CPGs is a costly undertaking. In proposing future directions for national guidelines for COPD management in Europe, Miravitlles et al. eloquently described the challenges facing developers of CPGs [84]. Apart from time, funding, and labour, developers are required to balance decisions concerning essential and non-essential CPG content (especially in CPGs planned for single chronic conditions where multiple comorbidities exist), frameworks for the choice and rating of evidence (quantitative hierarchies versus consensus opinion), stakeholder representation within CPG development, intended target audience, and strategies for the effective dissemination of CPGs.

A key factor determining whether content is essential for inclusion within CPGs is the availability of supporting evidence at the time of the guideline development [85]. Despite the steady growth in studies reporting pain prevalence in people with COPD, few studies explore pain aetiology in this population and almost none explore pain management strategies beyond palliative or end of life care. Similar to the stated inability of van Dam van Isselt et al. (2014) to identify a single study reporting a specific intervention strategy to manage pain in people with COPD [3], we also failed to identify such studies. However, the rehabilitation community is clearly working towards this through the confirmation of appropriate pain assessment instruments [86] and qualitative explorations of the pain experiences in people with COPD in order to develop a pain management program specific to this population $[87,88]$.

Perhaps a surprising finding of this review, however, was the small number of CPGs that reported the prevalence of chronic pain in COPD or listed pain as a common comorbidity. The sole CPG to report specific pain prevalence in COPD (Finland 2014 [47]) did so in the context of pain being 
one of the most common symptoms of advanced COPD (prevalence of pain 30-70\% in the section Palliative Care). This absence might be partially explained by the time frames for publication of pain prevalence studies and lead-time requirements for the development and publication of COPD CPGs. By the end of 2018, over 30 studies had been published confirming high pain prevalence in people with COPD (Figure 3). Of these, seven were published prior to the sampling frame for this review (2006) $[4,7,8,21,27,28,36]$. At best, by the midpoint of this review (2010), 11 studies reporting on pain prevalence in this population would have been available to developers of the six CPGs published between 2006-2009 [48,80-82,89-91]. By 2016, there were 26 papers available as a potential evidence base to the 30 CPGs published between 2010-2015 [46,47,62-79,92-102]. Across 2017 to 2018, at least another nine studies have been published providing estimates of pain prevalence in people with COPD, which would be available to developers of future CPGs or of CPGs currently underway or being updated $[6,19,20,26,31-35]$.

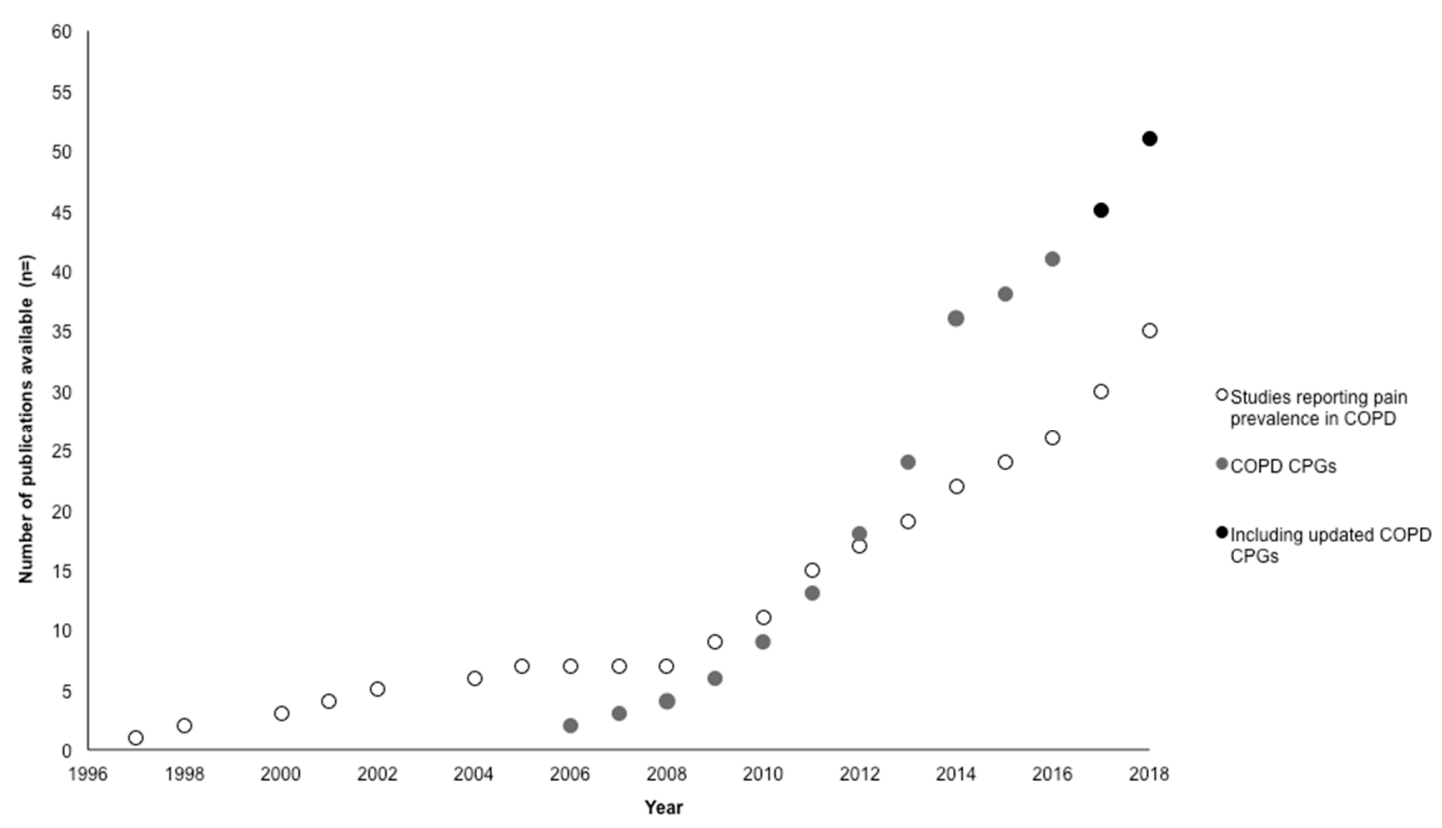

Figure 3. Publication of studies reporting pain prevalence in people with COPD versus COPD clinical practice guidelines (CPGs) included in this review and update.

While the evidence base supporting chronic pain as a comorbidity in people with COPD is relatively small (but growing), there are various other factors that may contribute to the under recognition of this symptom. In the older general population, of which people with COPD form a subgroup, chronic pain, especially non-cancer related pain, is often under reported, assessed, and managed [103]. This has been suggested to reflect the deficiencies in health professional education concerning chronic pain [104], a "side-lining" of pain management as a consequence of the current focus on the opioid epidemic [104], the ongoing tensions regarding the use of opioids to palliate dyspnoea in people with respiratory disease $[105,106]$, and/or the persistence of erroneous beliefs that pain is an expected or natural consequence of aging or will inevitably worsen over time or that putting up with pain (stoicism) will result in better pain tolerance [107].

\subsection{Beyond Prevalence: Could a Case be Made for Considering Pain within CPGs for Management of People} with COPD?

There is compelling evidence that in people with COPD, (1) persistent pain is more common than in people of similar age/sex in the general population [11,30,34]; (2) the risk of chronic non-cancer pain is increased [29]; and (3) for many, the pain severity should warrant not only assessment but also palliation. In a recent cross-sectional population-based analysis of Norwegians with COPD $(n=1199)$; 
without COPD but with arthritis $(n=8582)$, heart disease $(n=4109)$, or diabetes $(n=1254)$; or without any disease $(n=18,811)$, over half the COPD sample $(56.9 \%)$ rated pain severity in the preceding four weeks as moderate to very severe, which was twice the amount of people without disease $(29.5 \%)$ and second only to people with arthritis (71.9\%) [34].

In people with COPD, the presence and severity of chronic pain has significant clinical implications. Compared to people with COPD without chronic pain, those with chronic pain have been reported to have more than double the total direct medical costs [30]. Pain has shown to be associated with poorer quality of life [108]; increased breathlessness, fatigue [2,26], and depression [35]; and impaired sleep quality [20]. Furthermore, in a population where low levels of physical activity and sedentarism are common $[109,110]$, physical activity levels are negatively associated with pain severity $[35,111]$. People with COPD who live with chronic pain are less physically active than similarly aged people without COPD as well as their peers with COPD and no pain [35,111]. For this population, an inability to participate in evidence-based interventions such as pulmonary rehabilitation could be anticipated and may provide a partial explanation for the less than optimal uptake and completion rates. Whether palliating chronic pain in people with COPD leads to improvements in quality of life, symptom burden, depression, and/or participation in physical activity, however, remains to be explored.

\subsection{Strengths and Limitations}

This systematic review was strengthened by the comprehensive search strategy used and by not setting limitations for the publication language. Over half (21 of 41 CPGs) of included CPGs were published in a language other than English. A limitation of this review, however, is that the translation of these CPGs was not done via the back-translation method, which is the recommended method when translating documents between languages. This review was further limited by extracting only data on mentions of "pain" and not relevant synonyms. This may have missed some information around recommendations and strategies focused on pain, particularly in non-English CPGs.

\section{Conclusions}

Chronic pain is common in people with COPD and adversely impacts quality of life, mood, breathlessness, and participation in physical activity and activities of daily living. Yet, few CPGs address the symptom of pain. The impact of effective pain management on disease trajectory, symptom burden, or quality of life in people with COPD is currently unknown. Consequently, CPG developers would need to base treatment recommendations on expert consensus or to default to CPGs created for the assessment or management of chronic pain developed for the general population. It has been estimated that there were 384 million COPD cases in 2010 [50], which is greater than the current 2018 estimate for the total population of the United States of America. Based on this 2010 estimate, if there was a country inhabited only by people with COPD and using the most conservative estimate of pain prevalence in this group (28\%) [21], the number of inhabitants living with chronic pain equates to a population of at least 107,520,000: a megacity of chronic pain. From a prevalence point of view, at least, is there now enough evidence to warrant the inclusion of chronic pain within CPGs for COPD as a common clinical issue for people with COPD?

Supplementary Materials: The following are available online at http:/ /www.mdpi.com/2227-9032/7/1/15/s1, Table S1: The search strategy conducted in OVID Medline; Table S2: The clinical practice guidelines for the management of COPD included in this review; Table S3: The mentions of "pain" in the clinical practice guidelines for the management of COPD.

Author Contributions: Conceptualization, H.L. and M.T.W.; methodology, H.L., M.T.W., G.W., and K.B.; validation, G.W. and H.L.; formal analysis, H.L. and G.W.; data curation, H.L. and G.W.; writing-original draft preparation, M.T.W. and H.L.; writing-review and editing, K.B., G.W., H.L., and M.T.W.; visualization, H.L. and M.T.W.; supervision, M.T.W., K.B., and H.L.

Funding: This research received no external funding. Hayley Lewthwaite was supported by an Australian Government Research Training Program scholarship. 
Acknowledgments: The authors wish to express their gratitude to the following translators who assisted in extracting data from guidelines which were not published in English: Gina Mincham, Hanna Tervonen, Flynn Slattery, Katja Seifken, Tanja Effing, Timothy Olds, Simon Kirkegaard, Yesenia Opitz, Mohsen Jamali, Wendy Geng, Larisa Bobrovskaya, Helen Woo, Alla Evans, Barbara Roszkowski, and Magnus Ekstrom. We also wish to acknowledge the work of and to thank the research team involved in the development of the protocol of the previous systematic review which this review is based on: Hayley Lewthwaite, Tanja Effing, Timothy Olds, Marie Williams, Sarah McQuillen (Academic librarian who assisted in the development of the search strategy), and Peter Frith (reviewed list of guidelines).

Conflicts of Interest: The authors declare no conflict of interest.

\section{References}

1. HajGhanbari, B.; Holsti, L.; Road, J.D.; Darlene Reid, W. Pain in people with chronic obstructive pulmonary disease (COPD). Respir. Med. 2012, 106, 998-1005. [CrossRef] [PubMed]

2. Lee, A.L.; Harrison, S.L.; Goldstein, R.S.; Brooks, D. Pain and its clinical associations in individuals with COPD: A systematic Review. Chest 2015, 147, 1246-1258. [CrossRef]

3. van Dam van Isselt, E.F.; Groenewegen-Sipkema, K.H.; Spruit-van Eijk, M.; Chavannes, N.H.; de Waal, M.W.M.; Janssen, D.J.A.; Achterberg, W.P. Pain in patients with COPD: A systematic review and meta-analysis. BMJ Open 2014, 4. [CrossRef]

4. Claessens, M.T.; Lynn, J.; Zhong, Z.; Desbiens, N.A.; Phillips, R.S.; Wu, A.W.; Harrell, F.E., Jr.; Connors, A.F., Jr. Dying with lung cancer or chronic obstructive pulmonary disease: Insights from SUPPORT. Study to Understand Prognoses and Preferences for Outcomes and Risks of Treatments. J. Am. Geriatr. Soc. 2000, 48, S146-S153. [CrossRef]

5. Lohne, V.; Heer, H.C.; Andersen, M.; Miaskowski, C.; Kongerud, J.; Rustoen, T. Qualitative study of pain of patients with chronic obstructive pulmonary disease. Heart Lung 2010, 39, 226-234. [CrossRef] [PubMed]

6. van Dam van Isselt, E.F.; Groenewegen-Sipkema, K.H.; van Eijk, M.; Chavannes, N.H.; Achterberg, W.P. Pain in patients with chronic obstructive pulmonary disease indicated for post-acute pulmonary rehabilitation. Chron. Respir. Dis. 2018, 16. [CrossRef] [PubMed]

7. Lynn, J.; Teno, J.M.; Phillips, R.S.; Wu, A.W.; Desbiens, N.; Harrold, J.; Claessens, M.T.; Wenger, N.; Kreling, B.; Connors, A.F. Perceptions by family members of the dying experience of older and seriously ill patients. SUPPORT Investigators. Study to Understand Prognoses and Preferences for Outcomes and Risks of Treatments. Ann. Intern. Med. 1997, 126, 97-106. [CrossRef]

8. Synnot, A.; Williams, M. Low back pain in individuals with chronic airflow limitation and their partners-A preliminary prevalence study. Physiother. Res. Int. 2006, 7, 215-227. [CrossRef]

9. Janssen, D.J.; Spruit, M.A.; Uszko-Lencer, N.H.; Schols, J.M.; Wouters, E.F. Symptoms, comorbidities, and health care in advanced chronic obstructive pulmonary disease or chronic heart failure. J. Palliat. Med. 2011, 14, 735-743. [CrossRef] [PubMed]

10. White, P.; White, S.; Edmonds, P.; Gysels, M.; Moxham, J.; Seed, P.; Shipman, C. Palliative care or end-of-life care in advanced chronic obstructive pulmonary disease: A prospective community survey. Br. J. Gen. Pract. 2011, 61, e362-e370. [CrossRef]

11. Bentsen, S.B.; Rustoen, T.; Miaskowski, C. Prevalence and characteristics of pain in patients with chronic obstructive pulmonary disease compared to the Norwegian general population. J. Pain 2011, 12, 539-545. [CrossRef] [PubMed]

12. Bentsen, S.B.; Rustøen, T.; Miaskowski, C. Differences in subjective and objective respiratory parameters in patients with chronic obstructive pulmonary disease with and without pain. Int. J. Chron. Obstruct. Pulm. Dis. 2012, 7, 137-143. [CrossRef] [PubMed]

13. Bentsen, S.B.; Gundersen, D.; Assmus, J.; Bringsvor, H.; Berland, A. Multiple symptoms in patients with chronic obstructive pulmonary disease in Norway. Nurs. Health Sci. 2013, 15, 292-299. [CrossRef]

14. Borge, C.R.; Wahl, A.K.; Moum, T. Association of breathlessness with multiple symptoms in chronic obstructive pulmonary disease. J. Adv. Nurs. 2010, 66, 2688-2700. [CrossRef] [PubMed]

15. Heneghan, N.; Adab, P.; Jackman, S.; Balanos, G. Musculoskeletal dysfunction in chronic obstructive pulmonary disease (COPD): An observational study. Int. J. Ther. Rehabil. 2015, 22. [CrossRef] 
16. Janssen, D.J.A.; Wouters, E.F.M.; Parra, Y.L.; Stakenborg, K.; Franssen, F.M.E. Prevalence of thoracic pain in patients with chronic obstructive pulmonary disease and relationship with patient characteristics: A cross-sectional observational study. BMC Pulm. Med. 2016, 16, 16-47. [CrossRef]

17. Romem, A.; Tom, S.E.; Beauchene, M.; Babington, L.; Scharf, S.M.; Romem, A. Pain management at the end of life: A comparative study of cancer, dementia, and chronic obstructive pulmonary disease patients. Palliat. Med. 2015, 29, 464-469. [CrossRef] [PubMed]

18. Christensen, V.L.; Holm, A.M.; Kongerud, J.; Bentsen, S.B.; Paul, S.M.; Miaskowski, C.; Rustøen, T. Occurrence, characteristics, and predictors of pain in patients with chronic obstructive pulmonary disease. Pain Manag. Nurs. 2016, 17, 107-118. [CrossRef]

19. Chen, Y.W.; Camp, P.G.; Coxson, H.O.; Road, J.D.; Guenette, J.A.; Hunt, M.A.; Reid, W.D. Comorbidities that cause pain and the contributors to pain in individuals with chronic obstructive pulmonary disease. Arch. Phys Med. Rehabil. 2017, 98, 1535-1543. [CrossRef]

20. Chen, Y.W.; Camp, P.G.; Coxson, H.O.; Road, J.D.; Guenette, J.A.; Hunt, M.A.; Reid, W.D. A comparison of pain, fatigue, dyspnea and their impact on quality of life in pulmonary rehabilitation participants with COPD. COPD 2018, 15, 65-72. [CrossRef]

21. Walke, L.M.; Gallo, W.T.; Tinetti, M.E.; Fried, T.R. The burden of symptoms among community-dwelling older persons with advanced chronic disease. Arch. Intern. Med. 2004, 164, 2321-2324. [CrossRef]

22. Blinderman, C.D.; Homel, P.; Billings, J.; Tennstedt, S.; Portenoy, R.K. Symptom distress and quality of life in patients with advanced chronic obstructive pulmonary disease. J. Pain Symptom Manag. 2009, 38, 115-123. [CrossRef]

23. Srirat, C.; Hanucharurnkul, S.; Aree-Ue, S.; Viwatwongkasem, C.; Junda, T. Symptom distress, cluster, and management in Thais with COPD. Pac. Rim Int. J. Nurs. Res. 2014, 18, 244-262.

24. Eckerblad, J.; Tödt, K.; Jakobsson, P.; Unosson, M.; Skargren, E.; Kentsson, M.; Theander, K. Symptom burden in stable COPD patients with moderate or severe airflow limitation. Heart Lung 2014, 43, 351-357. [CrossRef] [PubMed]

25. HajGhanbari, B.; Yamabayashi, C.; Garland, R.J.; Road, J.D.; Reid, D.W. The relationship between pain and comorbid health conditions in people with chronic obstructive pulmonary disease. Cardiopulm. Phys. Ther. J. 2014, 25, 29-35. [CrossRef]

26. Bentsen, S.B.; Miaskowski, C.; Cooper, B.A.; Christensen, V.L.; Henriksen, A.H.; Holm, A.M.; Rustoen, T. Distinct pain profiles in patients with chronic obstructive pulmonary disease. Int. J. Chron. Obstruct. Pulm. Dis. 2018, 13, 801-811. [CrossRef] [PubMed]

27. Edmonds, P.; Karlsen, S.; Khan, S.; Addington-Hall, J. A comparison of the palliative care needs of patients dying from chronic respiratory diseases and lung cancer. Palliat. Med. 2001, 15, 287-295. [CrossRef]

28. Elkington, H.; White, P.; Addington-Hall, J.; Higgs, R.; Edmonds, P. The healthcare needs of chronic obstructive pulmonary disease patients in the last year of life. Palliat. Med. 2005, 19, 485-491. [CrossRef]

29. Rashiq, S.; Dick, B.D. Factors associated with chronic non-cancer pain in the Canadian population. Pain Res. Manag. 2009, 14, 454-460. [CrossRef] [PubMed]

30. Roberts, M.H.; Mapel, D.W.; Hartry, A.; Von Worley, A.; Thomson, H. Chronic pain and pain medication use in chronic obstructive pulmonary disease. A cross-sectional study. Ann. Am. Thorac. Soc. 2013, 10, 290-298. [CrossRef]

31. Xiao, T.; Zhou, X.; He, Y.; Chen, Y.; Qiu, H.; Zhang, S.; Wei, X.; Wu, K.; Ruan, X.; Wang, N. Pain problems for patients with mild and moderate chronic obstructive pulmonary disease-A community-based study in Shanghai. J. Pain Res. 2017, 10, 2247-2252. [CrossRef]

32. Chen, Y.W.; Coxson, H.O.; Coupal, T.M.; Lam, S.; Munk, P.L.; Leipsic, J.; Reid, W.D. The contribution of thoracic vertebral deformity and arthropathy to trunk pain in patients with chronic obstructive pulmonary disease (COPD). Respir. Med. 2018, 137, 115-122. [CrossRef] [PubMed]

33. de Miguel-Díez, J.; López-de-Andrés, A.; Hernandez-Barrera, V.; Jimenez-Trujillo, I.; del Barrio, J.L.; Puente-Maestu, L. Prevalence of pain in COPD patients and associated factors: Report from a population-based study. Clin. J. Pain 2018, 34, 787-794. [CrossRef]

34. Andenæs, R.; Momyr, A.; Brekke, I. Reporting of pain by people with chronic obstructive pulmonary disease (COPD): Comparative results from the HUNT3 population-based survey. BMC Public Health 2018, 18, 181. [CrossRef] [PubMed] 
35. Lee, A.L.; Goldstein, R.S.; Brooks, D. Chronic pain in people with chronic obstructive pulmonary disease: Prevalence, clinical and psychological implications. Chronic. Obstr. Pulm. Dis. 2017, 4, 194-203. [CrossRef] [PubMed]

36. Skilbeck, J.; Mott, L.; Page, H.; Smith, D.; Hjelmeland-Ahmedzai, S.; Clark, D. Palliative care in chronic obstructive airways disease: A needs assessment. Palliat. Med. 1998, 12, 245-254. [CrossRef]

37. Roberts, M.H.; Mapel, D.W.; Thomson, H.N. The impact of chronic pain on direct medical utilization and costs in chronic obstructive pulmonary disease. Clinicoecon. Outcomes Res. 2015, 7, 173-184. [CrossRef]

38. Bordoni, B.; Marelli, F.; Morabito, B.; Sacconi, B.; Caiazzo, P.; Castagna, R. Low back pain and gastroesophageal reflux in patients with COPD: The disease in the breath. Int. J. Chron. Obstruct. Pulm. Dis. 2018, 13, 325-334. [CrossRef]

39. Lee, A.L.; Goldstein, R.S.; Chan, C.; Rhim, M.; Zabjek, K.; Brooks, D. Postural deviations in individuals with chronic obstructive pulmonary disease (COPD). Am. J. Respir. Crit. Care Med. 2018, 193. [CrossRef]

40. Vardar-Yagli, N.; Calik-Kutukcu, E.; Saglam, M.; Inal-Ince, D.; Arikan, H.; Coplu, L. The relationship between fear of movement, pain and fatigue severity, dyspnea level and comorbidities in patients with chronic obstructive pulmonary disease. Disabil. Rehabil. 2018. [CrossRef]

41. Moher, D.; Shamseer, L.; Clarke, M.; Ghersi, D.; Liberati, A.; Petticrew, M.; Shekelle, P.; Stewart, L.A.; PRISMA-P Group. Preferred reporting items for systematic review and meta-analysis protocols (PRISMA-P) 2015 statement. Syst. Rev. 2015, 4. [CrossRef]

42. Lewthwaite, H.; Effing, T.; Olds, T.; Williams, MT. Physical activity, sedentary behaviour and sleep in COPD guidelines: A systematic review. Chron. Respir. Dis. 2017, 14, 231-244. [CrossRef]

43. Japanese Respiratory Society [Guidelines for Diagnosis and Treatment of COPD (Chronic Obstructive Pulmonary Disease)]. Available online: http://www.jrs.or.jp/modules/info_bk/index.php?content_id=1 (accessed on 29 November 2018).

44. American Medical Directors Association COPD Management in the Long-Term Care Setting. Available online: http:/ / www.paltc.org/product-store/copd-management-cpg (accessed on 16 December 2015).

45. Thoracic Society of Thailand [Health Service Practice Guidelines Chronic Obstructive Pulmonary Disease 2010]. Available online: http:/ / www.thoracicsocietythai.org/guidelines / (accessed on 29 November 2018).

46. The Institute for Healthcare Improvement CBO [Guideline for the Diagnosis and Treatment of COPD Update March 2010]. Available online: http:/ /www.nvalt.nl/uploads/Mn/U9/MnU99pqRBYK7a_zStHhumA/ Richtlijn-Diagnostiek-en-behandeling-van-COPD-maart-2010.pdf (accessed on 27 April 2016).

47. Kankaanranta, H.; Harju, T.; Kilpelainen, M.; Mazur, W.; Lehto, J.T.; Katajisto, M.; Peisa, T.; Meinander, T.; Lehtimäki, L. Diagnosis and pharmacotherapy of stable chronic obstructive pulmonary disease: The Finnish guidelines. Basic Clin. Pharmacol. Toxicol. 2015, 116, 291-307. [CrossRef] [PubMed]

48. Vogelmeier, C.; Buhl, R.; Criee, C.P.; Gillissen, A.; Kardos, P.; Kohler, D.; Magnussen, H.; Morr, H.; Nowak, D.; Pfeiffer-Kascha, D.; et al. Guidelines for the diagnosis and therapy of COPD issued by Deutsche Atemwegsliga and Deutsche Gesellschaft fur Pneumologie und Beatmungsmedizin. Pneumologie 2007, 61, e1-e40. [CrossRef] [PubMed]

49. Norwegian Directorate of Health [COPD National Academic Policy and Guidelines for Prevention, Diagnosis and Care]. Available online: https:/ /helsedirektoratet.no/Lists/Publikasjoner/Attachments /847/Nasjonalfaglig-retningslinje-og-veileder-for-forebygging-diagnostisering-og-oppf $\backslash \mathrm{T} 1 \backslash$ olging-IS-2029.pdf (accessed on 29 November 2018).

50. From the Global Strategy for the Diagnosis, Management and Prevention of COPD Global Initiative for Chronic Obstructive Lung Disease (GOLD) 2019. Available online: https://goldcopd.org/wp-content/ uploads/2018/11/GOLD-2019-v1.7-FINAL-14Nov2018-WMS.pdf (accessed on 12 November 2018).

51. The Lung Foundation Australia the COPD-X plan Australian and New Zealand Guidelines for the Management of Chronic Obstructive Pulmonary Disease 2018. Version 2.55. August 2018. Available online: http:/ / copdx.org.au/copd-x-plan/ (accessed on 17 December 2018).

52. Vogelmeier, C.; Buhl, R.; Burghuber, O.C.; Criee, C.P.; Ewig, S.; Godnic-Cvar, J.; Hartl, S.; Herth, F.; Kardos, P.; Kenn, K.; et al. Guideline for the Diagnosis and Treatment of COPD Patients Issued by the German Respiratory Society and the German Atemwegsliga in Cooperation with the Austrian Society of Pneumology. Pneumologie 2018, 72, 253-308. [PubMed] 
53. Stolz, D.; Barandun, J.; Borer, H.; Bridevaux, P.O.; Brun, P.; Brutsche, M.; Clarenbach, C.; Eich, C.; Fiechter, R.; Frey, M.; et al. Diagnosis, Prevention and Treatment of Stable COPD and Acute Exacerbations of COPD: The Swiss Recommendations. Respiration 2018, 96, 382-398. [CrossRef]

54. Park, Y.B.; Rhee, C.K.; Yoon, H.K.; Oh, Y.M.; Lim, S.Y.; Lee, J.H.; Yoo, K.H.; Ahn, A.; Committee of the Korean COPD Guideline 2018. Revised (2018) COPD Clinical Practice Guideline of the Korean Academy of Tuberculosis and Respiratory Disease: A Summary. Tuberc. Respir. Dis. 2018, 81, 261-273. [CrossRef] [PubMed]

55. Ministry of Health British Columbia Chronic Obstructive Pulmonary Disease (COPD): Diagnosis and Management. Available online: https:/ /bit.ly/2AA2spd (accessed on 29 November 2018).

56. Mahboub, B.H.; Vats, M.G.; Al Zaabi, A.; Iqbal, M.N.; Safwat, T.; Al-Hurish, F.; Miravitlles, M.; Singh, D.; Asad, K.; Zeineldine, S.; et al. Joint statement for the diagnosis, management, and prevention of chronic obstructive pulmonary disease for Gulf Cooperation Council countries and Middle East-North Africa region, 2017. Int. J. Chron. Obstruct. Pulm. Dis. 2017, 12, 2869-2890. [CrossRef] [PubMed]

57. University of Michigan Health System Chronic Obstructive Pulmonary Disease. Available online: www. uofmhealth.org/provider/clinical-care-guidelines (accessed on 29 November 2018).

58. National Board of Health and Welfare Socialstyrelsen [National Guidelines for Care for Asthma and COPD—Support for Management]. Available online: http:/ /www.socialstyrelsen.se/Lists/Artikelkatalog/ Attachments/20858/2018-1-36.pdf (accessed on 5 December 2018).

59. Lim, T.K.; Chee, C.B.; Chow, P.; Chua, G.S.W.; Eng, S.K.; Goh, S.K.; Kng, K.K.; Lim, W.H.; Ng, T.P.; Ong, T.H.; et al. Ministry of Health Clinical Practice Guidelines: Chronic Obstructive Pulmonary Disease. Singap. Med. J. 2018, 59, 76-86. [CrossRef]

60. From the Global Strategy for the Diagnosis, Management and Prevention of COPD. Global Initiative for Chronic Obstructive Lung Disease (GOLD) 2015. Available online: http:/ / www.goldcopd.org/ (accessed on 27 April 2016).

61. The Lung Foundation The COPD-X Plan Australian and New Zealand Guidelines for the Management of Chronic Obstructive Pulmonary Disease 2017. Version 2.49. March 2017. Available online: http:/ / copdx.org. au/copd-x-plan/ (accessed on 1 April 2017).

62. NHG Working Group on Asthma and COPD in Adults. [NHG standard COPD (Third revision)]. Huisarts Wet. 2015, 58, 198-211.

63. Khan, J.H.; Lababidi, H.M.; Al-Moamary, M.S.; Zeitouni, M.O.; AL-Jahdali, H.H.; Al-Amoudi, O.S.; Wali, S.O.; Idrees, M.M.; Al-Shimemri, A.A.; Al Ghobain, M.O.; et al. The Saudi guidelines for the diagnosis and management of COPD. Ann. Thorac. Med. 2014, 9, 55-76. [PubMed]

64. Gupta, D.; Agarwal, R.; Aggarwal, A.N.; Maturu, V.N.; Dhooria, S.; Prasad, K.T.; Sehgal, I.S.; Yenge, L.B.; Jindal, A.; Singh, N.; et al. Guidelines for diagnosis and management of chronic obstructive pulmonary disease: Joint ICS/NCCP (I) recommendations. Lung India 2013, 30, 228-267. [CrossRef]

65. Bettoncelli, G.; Blasi, F.; Brusasco, V.; Centanni, S.; Corrado, A.; De Benedetto, F.; De Michele, F.; Di Maria, G.U.; Donner, C.F.; Falcone, F.; et al. The clinical and integrated management of COPD. An official document of AIMAR (Interdisciplinary Association for Research in Lung Disease), AIPO (Italian Association of Hospital Pulmonologists), IMER (Italian Society of Respiratory Medicine), SIMG (Italian Society of General Medicine). Multidiscip. Respir. Med. 2014, 9. [CrossRef]

66. Department of Veterans Affairs, Department of Defence VA/DoD Clinical Practice Guideline for the Management of Chronic Obstructive Pulmonary Disease 2014. Available online: http:/ /www.healthquality. va.gov/guidelines/cd/copd/ (accessed on 27 April 2016).

67. Sliwinski, P.; Gorecka, D.; Jassem, E.; Pierzchala, W. [Polish Respiratory Society guidelines for chronic obstructive pulmonary disease]. Pneumonol. Alergol. Polska 2014, 82, 227-263.

68. High Authority of Health [Care Initiative Guide: Chronic Obstructive Pulmonary Disease]. Available online: http:/ / www.has-sante.fr/portail/upload/docs/application/pdf/2012-04/guide_parcours_de_ soins_bpco_finale.pdf (accessed on 27 April 2016).

69. Kocabaş, A.; Atış, S.; Çöplü, L.; Erdinç, E.; Ergan, B.; Gürgün, A.; Köktürk, N.; Polatlı, M.; Şen, E.; Yıldırım, N. Kronik Obstrüktif Akciğer Hastaliği (KOAH) Koruma, Tani ve Tedavi Raporu 2014. Turk. Thorac. J. 2014, 15, S1-S76.

70. Korea Foundation for Tuberculosis and Respiratory Disease COPD 진료지침 2014 개정. Available online: http:/ / www.kaim.or.kr/files/guide/호흡기_02.pdf (accessed on 29 November 2018). 
71. Miravitlles, M.; Soler-Cataluña, J.J.; Calle, M.; Molina, J.; Almagro, P.; Quintano, J.A.; Riesco, J.A.; Triqueros, J.A.; Piñera, P.; Simón, A.; et al. Spanish guideline for COPD (GesEPOC). Update 2014. Arch. Bronconeumol. 2014, 50. [CrossRef]

72. Task Force of GesEPOC. Clinical practice guideline for the diagnosis and treatment of patients with chronic obstructive pulmonary disease (COPD)—Spanish guideline for COPD (GesEPOC). Arch. Bronconeumol. 2012, 48. [CrossRef]

73. Koblizek, V.; Chlumsky, J.; Zindr, V.; Neumannova, K.; Zatloukal, J.; Zak, J.; Sedlak, V.; Kocianova, J.; Zatloukal, J.; Hejduk, K.; et al. Chronic obstructive pulmonary disease: Official diagnosis and treatment guidelines of the Czech Pneumological and Phthisiological Society; a novel phenotypic approach to COPD with patient-oriented care. Biomed. PAP 2013, 157, 189-201. [CrossRef]

74. Chinese Medical Association Respiratory Diseases Society Chronic Obstructive Pulmonary Diseases Group. Guidelines for the diagnosis and treatment of chronic obstructive pulmonary disease (revised edition 2013). Chin. J. Front. Med. 2014, 6, 67-80.

75. Ministry of Health Chile [Clinical Guide Chronic Obstructive Pulmonary Disease COPD]. Available online: http:/ / www.supersalud.gob.cl/difusion/572/articles-655_recurso_1.pdf (accessed on 27 April 2016).

76. Ministry of Health Ukraine [Chronic Obstructive Pulmonary Disease Adapted Clinical Guidelines Based on Evidence]. Available online: http://www.dec.gov.ua/mtd/_hozl.html (accessed on 29 April 2016).

77. The Algerian Society of Pneumopathophysiology. [The Chronic Obstructive Pulmonary Disease Practical Guide for the Practitioner]. Available online: http://www.sapp-algeria.org/PDF/guide_bpco_2011.pdf (accessed on 27 April 2016).

78. Abdool-Gaffar, M.; Ambaram, A.; Ainslie, G.; Bolliger, C.; Feldman, C.; Geffen, L.; Irusen, E.M.; Joubert, J.; Lalloo, U.G.; Mabaso, T.T.; et al. Guideline for the management of chronic obstructive pulmonary disease: 2011 update. S. Afr. Med. J. 2011, 101, 63-73.

79. National Institute for Health and Care Excellence Chronic Obstructive Pulmonary Disease: Management of Chronic Obstructive Pulmonary Disease in Adults in Primary and Secondary Care (Update Guideline). Available online: https:/ / www.nice.org.uk/guidance/conditions-and-diseases/respiratory-conditions / chronic-obstructive-pulmonary-disease (accessed on 13 April 2016).

80. O’Donnell, D.E.; Aaron, S.; Bourbeau, J.; Hernandez, P.; Marciniuk, D.D.; Balter, M.; Ford, G.; Gervais, A.; Goldstein, R.; Hodder, R.; et al. Canadian Thoracic Society recommendations for management of chronic obstructive pulmonary disease-2007 update. Can. Respir J. 2007, 5B-32B. [CrossRef] [PubMed]

81. O’Donnell, D.E.; Hernandez, P.; Kaplan, A.; Aaron, S.; Bourbeau, J.; Marciniuk, D.; Balter, M.; Ford, G.; Gervais, A.; Lacasse, Y.; et al. Canadian Thoracic Society recommendations for management of chronic obstructive pulmonary disease-2008 update-highlights for primary care. Can. Respir J. 2008, 15, 1A-8A. [CrossRef] [PubMed]

82. Ministry of Health Malaysia, Academy of Medicine Malaysia, Malaysian Thoracic Society Management of Chronic Obstructive Pulmonary Disease 2009. Available online: http:/ /www.moh.gov.my / attachments / 4749.pdf (accessed on 29 April 2016).

83. Solano, J.P.; Gomes, B.; Higginson, I.J. A comparison of symptom prevalence in far advanced cancer, AIDS, heart disease, chronic obstructive pulmonary disease and renal disease. J. Pain Symptom Manag. 2006, 31, 58-69. [CrossRef]

84. Miravitlles, M.; Roche, N.; Cardoso, J.; Halpin, D.; Aisanov, Z.; Kankaanranta, H.; Koblizek, V.; Sliwinski, P.; Bjermer, L.; Tamm, M.; et al. Chronic obstructive pulmonary disease guidelines in Europe: A look into the future. Respir. Res. 2018, 19. [CrossRef] [PubMed]

85. Miravitlles, M.; Vogelmeier, C.; Roche, N.; Halpin, D.; Cardoso, J.; Chuchalin, A.G.; Kankaanranta, H.; Sandström, T.; Śliwiński, P.; Zatloukal, J.; et al. A review of national guidelines for management of COPD in Europe. Eur. Respir. J. 2016, 47, 625-637. [CrossRef]

86. Chen, Y.W.; HajGhanbari, B.; Road, J.D.; Coxson, H.O.; Camp, P.G.; Reid, W.D. Reliability and validity of the Brief Pain Inventory in individuals with chronic obstructive pulmonary disease. Eur. J. Pain 2018, 1718-1726. [CrossRef]

87. Lee, A.L.; Harrison, S.L.; Goldstein, R.S.; Brooks, D.J.P. An exploration of pain experiences and their meaning in people with chronic obstructive pulmonary disease. Physiother. Theory Pract. 2018, 34, 756-772. [CrossRef] 
88. Harrison, S.L.; Lee, A.L.; Elliott-Button, H.L.; Shea, R.; Goldstein, R.S.; Brooks, D.; Ryan, C.G.; Martin, D.J. The role of pain in pulmonary rehabilitation: A qualitative study. Int. J. Chron. Obstruct. Pulm. Dis. 2017, 12, 3289-3299. [CrossRef]

89. Doherty, D.E.; Belfer, M.H.; Brunton, S.; Fromer, L.; Morris, C.; Snader, T. Chronic obstructive pulmonary disease: Consensus recommendations for early diagnosis and treatment. J. Fam. Pract. 2006, 55, S1-S8.

90. Bellamy, D.; Bouchard, J.; Henrichsen, S.; Johansson, G.; Langhammer, A.; Reid, J.; van Weel, C.; Buist, S. International Primary Care Respiratory Group (IPCRG) Guidelines: Management of chronic obstructive pulmonary disease (COPD). Prim. Care Respir. J. 2006, 15, 48-57. [CrossRef]

91. Report of the Council on COPD and Pulmonary Rehabilitation Philippine College of Chest Physicians Clinical Practice Guidelines in the Diagnosis and Management of Chronic Obstructive Pulmonary Disease (COPD) in the Philippines. Available online: http://philchest.org/v3/wp-content/uploads/2013/05/ PHILIPPINES-COPD-CPGuidelines-2009.pdf (accessed on 29 November 2018).

92. French Language Pneumology Society. [Recommendation for clinical practice management of COPD]. Rev. Mal. Respir. 2010, 27, 522-548.

93. Huizar-Hernández, V.; Rodríguez-Parga, D.; Sánchez-Mécatl, M.Á.; Nájera-Cruz, M.P.; Alvarado-Fuentes, J.; del Pilar Torres-Arreola, L. [Clinical practice guideline diagnosis and treatment of chronic obstructive lung disease]. Rev. Med. Inst. Mex. Seguro Soc. 2011, 49, 89-100.

94. Guidelines and Protocols Advisory Committee Chronic Obstructive Pulmonary Disease (COPD). Available online: http://www2.gov.bc.ca/assets/gov/health/practitioner-pro/bc-guidelines/copd.pdf (accessed on 27 April 2016).

95. Qaseem, A.; Wilt, T.J.; Weinberger, S.E.; Hanania, N.A.; Criner, G.; Van der Molen, T.; Marciniuk, D.D.; Denberg, T.; Schünemann, H.; Wedzicha, W.; et al. Diagnosis and management of stable chronic obstructive pulmonary disease: A clinical practice guideline update from the American College of Physicians, American College of Chest Physicians, American Thoracic Society, and European Respiratory Society. Ann. Intern. Med. 2011, 155, 179-191. [CrossRef] [PubMed]

96. Figueroa Casas, J.C.; Schiavi, E.; Mazzei, J.A.; Lopez, A.M.; Rhodius, E.; Ciruzzi, J.; Sívori, M.; Grupo Recomendaciones De EPOC; Asociacion Argentina De Medicina Respiratoria. [Recommendations for the prevention, diagnosis and treatment of COPD in Argentina]. Medicina 2012, 72 (Suppl. S1), 1-33.

97. Danish Society of Respiratory Medicine Danske KOL-Guidelines [Danish COPD Guidelines]. Available online: https://www.lungemedicin.dk/fagligt/101-dansk-kol-retningslinje-2012/file.html (accessed on 29 November 2018).

98. University of Michigan Health System Chronic Obstructive Pulmonary Disease. Available online: http: //www.med.umich.edu/1info/FHP/practiceguides/copd/copd.pdf (accessed on 27 April 2016).

99. Department of Quality in Health [Diagnosis and Treatment of Chronic Obstructive Pulmonary Disease]. Available online: https://www.dgs.pt/directrizes-da-dgs/normas-e-circulares-normativas/norma-n0282011-de-30092011-atualizada-a-10092013-png.aspx (accessed on 29 November 2018).

100. Russi, E.; Karrer, W.; Brutsche, M.; Eich, C.; Fitting, J.; Frey, M.; Geiser, T.; Kuhn, M.; Nicod, L.; Quadri, F.; et al. Diagnosis and management of chronic obstructive pulmonary disease: The Swiss guidelines. Respiration 2013, 85, 160-174. [CrossRef]

101. Montes de Oca, M.; Varela, M.V.L.; Acuña, A.; Schiavi, E.; Rey, M.A.; Jardim, J.; Casas, A.; Tokumoto, A.; Torres Duque, C.A.; Ramírez-Venegas, A.; et al. [Latinoamericana COPD Guide-2014 Based on Evidence]. Arch. Bronconeumol. 2015, 3-43. [CrossRef]

102. Chuchalin, A.G.; Avdeev, S.N.; Aysanov, Z.R.; Belevskiy, A.S.; Leshchenko, I.V.; Meshcheryakova, N.N.; Ovcharenko, S.I.; Shmelevet, E.I. Russian Respiratory Society Federal guidelines on diagnosis and treatment of chronic obstructive pulmonary disease. Rus. Pulmonol. 2014, 3. [CrossRef]

103. Reid, M.C.; Eccleston, C.; Pillemer, K. Management of chronic pain in older adults. BMJ 2015, 350. [CrossRef] [PubMed]

104. Loeser, J.D.; Schatman, M.E. Chronic pain management in medical education: A disastrous omission. Postgrad. Med. 2017, 129, 332-335. [CrossRef] [PubMed]

105. Rocker, G.; Bourbeau, J.; Downar, J. The New “Opioid Crisis": Scientific Bias, Media Attention, and Potential Harms for Patients with Refractory Dyspnea. J. Palliat. Med. 2018, 21, 120-122. [CrossRef] 
106. Abernethy, A.P.; Currow, D.C.; Frith, P.; Fazekas, B.S.; McHugh, A.; Bui, C. Randomised, double blind, placebo controlled crossover trial of sustained release morphine for the management of refractory dyspnoea. BMJ 2003, 327, 523-528. [CrossRef] [PubMed]

107. Thielke, S.; Sale, J.; Reid, M.C. Aging: Are these 4 pain myths complicating care? J. Fam. Pract. 2012, 61, 666-670.

108. Borge, C.R.; Wahl, A.K.; Moum, T. Pain and quality of life with chronic obstructive pulmonary disease. Heart Lung 2011, 40, e90-e101. [CrossRef] [PubMed]

109. Pitta, F.; Troosters, T.; Spruit, M.A.; Probst, V.S.; Decramer, M.; Gosselink, R. Characteristics of physical activities in daily life in chronic obstructive pulmonary disease. Am. J. Respir. Crit Care Med. 2005, 171, 972-977. [CrossRef] [PubMed]

110. Hunt, T.; Williams, M.T.; Olds, T.S.; Dumuid, D. Patterns of time use across the chronic obstructive pulmonary disease severity spectrum. Int. J. Environ. Res. Public Health 2018, 15, 533. [CrossRef]

111. HajGhanbari, B.; Garland, S.J.; Road, J.D.; Reid, W.D. Pain and physical performance in people with COPD. Respir. Med. 2013, 107, 1692-1699. [CrossRef]

(C) 2019 by the authors. Licensee MDPI, Basel, Switzerland. This article is an open access article distributed under the terms and conditions of the Creative Commons Attribution (CC BY) license (http://creativecommons.org/licenses/by/4.0/). 